\title{
A Painful Periungual Red Spot in a Patient with Onychodystrophy
}

\author{
Ahu Yorulmaz Basak Yalcin \\ Department of Dermatology, Ankara Numune Research and Education Hospital, Ankara, Turkey
}

\section{Question}

A 40-year-old male patient came to our outpatient clinic with a history of a painful red spot on the edge of his left middle finger for several days. He had a medical history of psoriasis, for which he was receiving $35 \mathrm{mg} /$ day of acitretin. His family history also revealed psoriasis in the father. Upon dermatological examination, we observed partial shedding of the nail plate and scaling of the nail bed and periungual skin on his left thumb and fore- finger. A gyrate-shaped scale on an erythematous base on the tip of the forefinger and a periungual dull red macule on the medial aspect of the middle finger were noticed (Fig. 1). The dermoscopic image of this lesion, which was obtained with a videodermoscope (MoleMax; Derma Instruments, Vienna, Austria) at 20-fold magnification, demonstrated a reddish homogeneous area and white rail lines (Fig. 2).

What is your diagnosis?

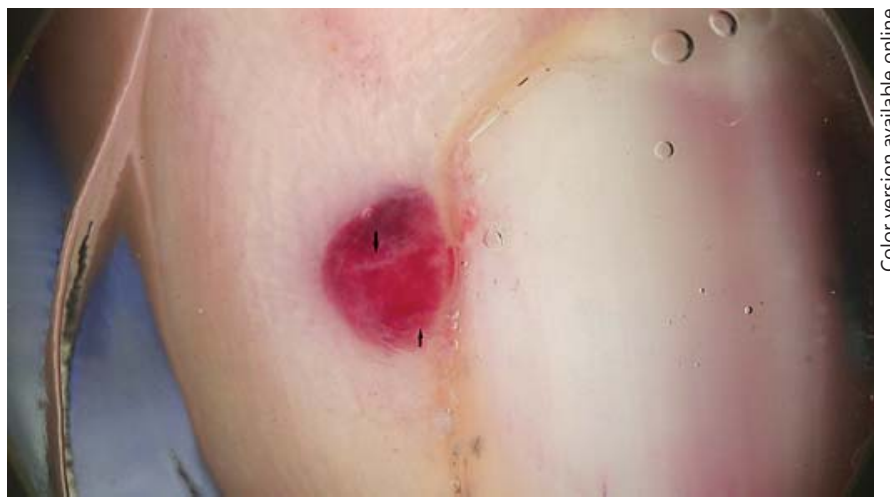

Fig. 2. Reddish homogeneous area and white rail lines $(\times 20)$.
Fig. 1. Partial loss of the nail plate and scaling of the nail bed and periungual skin on the left forefinger. Note the gyrate-shaped scale on the tip of the forefinger and the periungual erythematous-violaceous macule on the middle finger.

\section{KARGER}

(C) 2017 S. Karger AG, Basel

E-Mail karger@karger.com

www.karger.com/sad
Ahu Yorulmaz

Department of Dermatology

Ankara Numune Research and Education Hospital

Samanpazari, Altindag, TR-06100 Ankara (Turkey)

E-Mail ahuyor@gmail.com 


\section{Answer}

Acitretin-Induced Periungual Pyogenic Granuloma in Acrodermatitis Continua of Hallopeau

Acrodermatitis continua of Hallopeau (ACH) is a rare chronic inflammatory dermatosis characterized by sterile vesiculopustules affecting mainly the distal aspects of the phalanges. Although the clinical presentation of $\mathrm{ACH}$ is sufficiently distinctive for it to be considered a separate entity, the fact that in some patients the initial pustular eruption may eventually evolve into generalized pustular psoriasis has lead many authors to regard $\mathrm{ACH}$ as a localized variant of pustular psoriasis. Currently, $\mathrm{ACH}$ is recognized as a form of acropustular psoriasis. The typical clinical presentation of $\mathrm{ACH}$ consists of pustules and erosions on the distal aspects of the fingers and toes. Pustulation of the nail bed and matrix leads to nail dystrophy, which is primarily seen as nail plate destruction, shedding, onycholysis, and anonychia. Desiccation of pustules usually leaves red, glazed areas with scales [1-3]. The patient presented here had typical clinical features of ACH. The characteristic nail involvement with nail plate shedding, scaling of the nail bed, and also the tip toplocated gyrate-shaped scaling, which corresponded to a preceding pustule, pointed to the diagnosis of $\mathrm{ACH}$.

$\mathrm{ACH}$ is often refractory to treatment, and acitretin is one of the systemic agents that can be used to treat it [1-3]. Other than teratogenicity and other well-known side effects, including hepatotoxicity and mucocutaneous adverse reactions [4], acitretin is known as one of the most common causes of drug-induced nail pyogenic granuloma [5]. Piraccini et al. [5] thoroughly investigated the epidemiological and clinical features of nail pyogenic granuloma in a retrospective study, which revealed that out of 58 cases, 18 were found to have drug-induced nail pyogenic granuloma. Moreover, it was confirmed that retinoids were a major culprit in drug-induced nail pyogenic granuloma. Nail pyogenic granuloma is a vascular tumor characterized by reddish lesions on the periungual tissues and nail bed. The main characteristics of drug-induced nail pyogenic granuloma have been described as involvement of multiple nails and a predilection for toenail localization, presumably due to chronic trauma. It has been established that the lateral nail folds are the most commonly affected part of the perionychium. Besides, one of the typical features of retinoid-induced pyogenic granuloma is dose dependency, although exceptions have been reported. Even though the exact pathogenesis of retinoid-induced pyogenic granuloma remains to be elucidated, it has been proposed that the underlying mechanism may be related to the antiproliferative properties of retinoids, since retinoids de- crease the attachments between keratinocytes and cause nail brittleness, with penetration of fragments between the nail plate and the surrounding tissues [5].

Histopathological investigations are mostly essential to make a definitive diagnosis of pyogenic granuloma. However, it has been suggested that in cases where pyogenic granuloma regression occurs without surgery, such as in drug-induced nail pyogenic granuloma, histopathological analysis may not be carried out [5]. Our patient did not accept lesional skin biopsy and dermoscopy was the major performed diagnostic procedure. Thus, on the basis of the clinical and dermoscopic findings, we made a diagnosis of acitretin-induced periungual pyogenic granuloma in $\mathrm{ACH}$. Dermoscopy is a highly practical diagnostic technique, which has opened new dimensions in the morphologic evaluation of skin lesions. Over the years, dermoscopy has proven to be a valuable, noninvasive tool in the diagnosis of countless skin lesions [6]. So far, the dermoscopic features of pyogenic granuloma have been comprehensively described in different studies $[7,8]$. In a multicenter study with $96.7 \%$ sensitivity [8], a reddish homogeneous area was demonstrated to be the most frequent dermoscopic structure associated with pyogenic granulomas. In addition, another main dermoscopic structure, the "white rail lines," which are defined as whitish streaks or bands that intersect the pyogenic granuloma, showed a specificity of $81.4 \%$. In that study, the authors also defined 7 exclusive dermoscopic patterns of pyogenic granulomas, one of which includes the presence of a reddish homogeneous area and white rail lines [8]. This pattern was observed in our patient.

Here, we describe a patient with 2 different nail-related diseases who demonstrated typical clinical manifestations of $\mathrm{ACH}$ and nail pyogenic granuloma. We aimed to present the features of these diseases, highlighting the importance of dermoscopy in the diagnosis of pyogenic granuloma.

\section{Statement of Ethics}

The patient's consent was obtained.

\section{Disclosure Statement}

None of the authors declare any financial support or relationships that may pose a conflict of interest regarding this paper.

\section{Keywords}

Acrodermatitis continua of Hallopeau - Acitretin - Pyogenic granuloma - Onychodystrophy
Yorulmaz/Yalcin 


\section{References}

1 Burden AD, Kirby B: Psoriasis and related disorders; in Griffiths CEM, Barker J, Bleiker T, Chalmers R, Creamer D (eds): Rook's Textbook of Dermatology, ed 9. Oxford, John Wiley \& Sons, Ltd., 2016, pp 35, 40-43.

2 Sehgal VN, Verma P, Sharma S, Srivastava G, Aggarwal AK, Rasool F, Chatterjee K: Acrodermatitis continua of Hallopeau: evolution of treatment options. Int J Dermatol 2011;50: 1195-1211.
3 Piraccini BM, Fanti PA, Morelli R, Tosti A: Hallopeau's acrodermatitis continua of the nail apparatus: a clinical and pathological study of 20 patients. Acta Derm Venereol 1994;74:65-67.

4 Dunn LK, Gaar LR, Yentzer BA, O’Neill JL, Feldman SR: Acitretin in dermatology: a review. J Drugs Dermatol 2011;10:772-782.

5 Piraccini BM, Bellavista S, Misciali C, Tosti A, de Berker D, Richert B: Periungual and subungual pyogenic granuloma. Br J Dermatol 2010;163:941-953.
6 Russo T, Piccolo V, Lallas A, Argenziano G: Recent advances in dermoscopy. F1000Res 2016;5:F1000 Faculty Rev-184.

7 Zaballos P, Llambrich A, Cuéllar F, Puig S, Malvehy J: Dermoscopic findings in pyogenic granuloma. Br J Dermatol 2006;154:11081111.

8 Zaballos P, Carulla M, Ozdemir F, Zalaudek I, Bañuls J, Llambrich A, Puig S, Argenziano G, Malvehy J: Dermoscopy of pyogenic granuloma: a morphological study. Br J Dermatol 2010;163:1229-1237. 